Pacific Journal of Mathematics

POINTWISE COMPACTNESS AND MEASURABILITY 


\title{
POINTWISE COMPACTNESS AND MEASURABILITY
}

\section{SURJIT SiNGH KHURANA}

\begin{abstract}
Among other results it is proved that if $(X, \mathfrak{A}, \mu)$ is a probability space, $E$ a Hausdorff locally convex space such that $\left(E^{\prime}, \sigma\left(E^{\prime}, E\right)\right)$ contains an increasing sequence of absolutely convex compact sets with dense union, and $f: X \rightarrow E$ weakly measurable with $f(X) \subset K$, a weakly compact convex subset of $E$, then $f$ is weakly equivalent to $g: X \rightarrow E$ with $g(X)$ contained in a separable subset of $K$.
\end{abstract}

In [8] and [9] some remarkable results are obtained for the pointwise compact subsets of measurable real-valued functions and some interesting applications to strongly measurable Banach spacevalued functions are established. In this paper we continue those ideas a little further. We first give a somewhat different proof of ([9], Theorem 1) and then apply it to give a generalization of classical Phillip's theorem ([5]). Also some result about equicontinuous subsets of $C(X)$, the space of all continuous real-valued functions on $\left(X, \tau_{\rho}\right)\left(\tau_{p}\right.$ is the lifting topology, $[10], p .59$; in [8] this topology is denoted by $T_{\rho}$ ) are obtained.

All locally convex spaces are taken over reals and notations of [6] are used. For a topological space $Y, C(Y)$ (resp. $C_{b}(Y)$ ) will denote the set of all (resp. all bounded) real-valued continuous functions of $Y . N$ will denote the set of natural numbers.

In this paper $(X, \mathfrak{A}, \mu)$ is a complete probability measure space. Let $\mathscr{L}$ be the set of all real-valued $\mathscr{A}$-measurable functions on $X$, $\mathscr{L}^{\infty}$, the essentially bounded elements of $\mathscr{L}$, and $M^{\infty}$, the bounded elements of $\mathscr{L}$. We fix a lifting, [10], $\rho: \mathscr{L}^{\infty} \rightarrow M^{\infty}$ and on $X$ we always take the lifting topology $\tau_{\rho}([10]$, p. 59). For $f \in \mathscr{L}, g \in \mathscr{L}$, we write $f=g$ if $f(x)=g(x), \forall x \in X$, and $f \equiv g$ if $f(x)=g(x)$, a.e. [ $е$ ]. For a Hausdorff locally convex space $E$, a function $f: X \rightarrow E$ is said to be weakly measurable if $h \circ f$ is $\mathfrak{A}$-measurable, $\forall h \in E^{\prime}$, the topological dual of $E$. Two weakly measurable functions $f_{i}: X \rightarrow E, i=1,2$, are said to be weakly equivalent if $h \circ f_{1} \equiv h \circ f_{2}$, $\forall h \in E^{\prime}$. The space $\mathscr{L}_{1}$ and norms $\|\cdot\|_{1}$ and $\|\cdot\|_{\infty}$ have the usual meanings. We shall call a topological space, countably compact if every sequence in it has a cluster point, and sequentially compact if every sequence has a convergent subsequence.

We start with a different proof of the following result of [9]. 
THEOREM 1 ([9], Theorem 1). Let $H$ be a subset of $\mathscr{L}$ such that for any $h_{1} \in H, h_{2} \in H, h_{1} \neq h_{2}$ implies $h_{1} \not \equiv h_{2}$. Then, with the pointwise topology on $H$, the following are equivalent:

(i) $H$ is sequentially compact;

(ii) $H$ is compact and metrizable.

If $H$ is convex, then each of (i) and (ii) is also equivalent to:

(iii) $H$ is compact;

(iv) $H$ is countably compact.

Proof. By ([6], Theorem 11.2, p. 187) each of (i), (ii), (iii), (iv) implies that $H$ is relatively compact in $R^{X}$, with product topology. Thus each of these conditions implies that $H$ is pointwise bounded. Denote by $\varphi$ the homeomorphism, $[0, \infty] \rightarrow[0,1], x \rightarrow x /(1+x)$. For any $\alpha \in I$, the directed net of all finite subsets of $H$, let $h_{\alpha}=$ $\sup \{|h|: h \in \alpha\}$, and $p_{\alpha}=\rho\left(\varphi \circ h_{\alpha}\right) . \quad\left\{p_{\alpha}\right\}$ is a monotone bounded net in $C_{b}(X)$, which is boundedly complete. Let $\sup p_{\alpha}=p \in C_{b}(X)$. This means there is an increasing sequence $\{\alpha(n)\} \subset I$ such that $p=$ $\sup p_{\alpha(n)}$ (this follows from the fact that $\mu(p)=\sup \mu\left(p_{\alpha}\right)$ ). Since $p_{\alpha} \equiv \emptyset \circ h_{\alpha}$, we get $p_{\alpha}^{-1}\{1\}$ is $\mu$-null, $\forall \alpha$. From this it follows that $K=p^{-1}\{1\}$ is $\mu$-null. Thus $q=\left(\phi^{-1} \circ p\right) \chi_{X / K}$ is a measurable function such that $|h| \leqq q$ a.e. $[\mu], \forall h \in H$.

(i) $\Leftrightarrow$ (ii) is simple ([8], Prop. 1, p. 197), the metric $d$ of (ii) being defined by $d(f, g)=\|(f-g) / 1+q\|_{1}$. (ii) $\Rightarrow$ (iii) and (iii) $\Rightarrow$ (iv) are trivial. Now we come to the proof of (iv) $\Rightarrow(\mathrm{i})$. Take a sequence $\left\{f_{n}^{\prime}\right\} \subset H$. Since $1 /(1+q) H$ is relatively weakly compact in $\left(\mathscr{L}_{1},\|\cdot\|_{1}\right)$ there exists a subsequence $\left\{f_{n}\right\}$ of $\left\{f_{n}^{\prime}\right\}$ and an $f_{0} \in \mathscr{L}_{1}$ such that $1 /(1+q) f_{n} \rightarrow f_{0}$ weakly. Thus there exists a sequence $\left\{g_{n}\right\}$ in the convex hull of $\left\{f_{n}: 1 \leqq n<\infty\right\}$ (note $\left\{g_{n}\right\} \subset H$ ) such that $1 /(1+q) g_{n} \rightarrow f_{0}$ a.e. $[\mu]$ (because a convergent sequence in $\left(\mathscr{L}_{1},\|\cdot\|_{1}\right)$ has a subsequence converging a.e. $[\mu])$. Taking $f$ to be a cluster point of $\left\{g_{n}\right\}$ in $H$, we get $1 /(1+q) f \equiv f_{0}(\mu)$. We claim $f_{n} \rightarrow f$ in $H$. If $f_{n} \nrightarrow f$ there exists an $x \in X$, an $\varepsilon>0$, and a subsequence $\left\{f_{n}^{\prime \prime}\right\}$ of $\left\{f_{n}\right\}$ such that one of the two following conditions are satisfied:

(i) $f_{n}^{\prime \prime}(x)>f(x)+\varepsilon, \forall n$;

(ii) $f_{n}^{\prime \prime}(x)<f(x)-\varepsilon, \forall n$.

Since $1 /(1+q) f_{n}^{\prime \prime} \rightarrow 1 /(1+q) f$ weakly, proceeding as before we get a sequence $\left\{g_{n}^{\prime \prime}\right\}$ in the convex hull of $\left\{f_{n}^{\prime \prime}: 1 \leqq n<\infty\right\}$ such that $1 /(1+q) g_{n}^{\prime \prime} \rightarrow 1 /(1+q) f$ a.e. [ $\left.\mu\right]$. If $f^{\prime \prime}$ is a cluster point of $\left\{g_{n}^{\prime \prime}\right\}$ in $H$ we get $f^{\prime \prime} \equiv f(\mu)$ but because of (i) or (ii), $f^{\prime \prime}(x) \neq f(x)$, a contradiction. This proves that $H$ is sequentially compact.

This result is also proved in [11] by a different method. 
By a classical theorem of Phillips [5], if $f: X \rightarrow E, E$ being a Banach space, is weakly measurable and $f(X)$ is relatively weakly compact in $E$, then $f$ is weakly equivalent to a strongly measurable function ([8], Theorem 3, p. 200). What one really needs to do is to find a weakly equivalent function $g$ such that $g(X)$ is separable. The next theorem is a generalization of Phillips' theorem.

THEOREM 2. Let (E, $\mathscr{T})$ be a Hausdorff locally convex space such that there exists an increasing sequence $\left\{A_{n}\right\}$ of absolutely convex compact subsets of $\left(E^{\prime}, \sigma\left(E^{\prime}, E\right)\right.$ ) whose union is dense in $\left(E^{\prime}, \sigma\left(E^{\prime}, E\right)\right.$ ). Suppose $f: X \rightarrow E$ is weakly measurable and $f(X) \subset K$, for some weakly compact convex subset of $E$. Then there exists a weakly measurable function $g: X \rightarrow E, g \equiv f(w)$ and $g(X) \subset K_{0}, a$ separable closed convex subset of $K$.

Proof. Since $\left(E, \sigma\left(E, E^{\prime}\right)\right)$ can be considered as a subspace of $R^{E^{\prime}}$, with product topology, $f$ can be considered as $f: X \rightarrow R^{E^{\prime}}$. For each $h \in E^{\prime}$, define $g(h)=\rho(h \circ f)$ and let $g: X \rightarrow R^{E^{\prime}},(g)_{h}=g(h), \forall h \in E^{\prime}$. $g$ is evidently continuous. If $g\left(x_{0}\right) \notin K$ for some $x_{0} \in X$, there exists, by separation theorem ([6], p. 65), an $h \in E^{\prime}$ such that $h \circ g\left(x_{0}\right)>$ $\sup (K)$. This is a contradiction since $h \circ f \leqq \sup h(K)$ implies $\rho(h \circ f) \leqq \sup h(K)$. Evidently $g \equiv f(w)$. Fix $n \in N$. By Theorem 1, $B_{n}=\left\{h \circ g: h \in A_{n}\right\}$, with the topology of pointwise convergence on $X$, is a compact metric space. We metrize $E$ by the seminorms $p_{n}$, $p_{n}(x)=\sup \left\{|h(x)|: h \in A_{n}\right\}$. We denote this metric topology by $\mathscr{T}_{0}$. For each $n, E_{n}=\left(C\left(B_{n}\right),\|\cdot\|\right)$ is a separable Banach space (here $\|\cdot\|$ is sup norm), and so $F=\prod_{n=1}^{\infty} E_{n}$ is a separable Frechet space. Let $X_{0}$ be the quotient space obtained from $X$ by the equivalent relation, $x \equiv y \Leftrightarrow g(x)=g(y)$. Each $x \in X_{0}$ gives rise to $x \in C\left(B_{n}\right), x(t)=t(x)$ for each $t \in B_{n}$, for every $n$. Thus $X_{0}$ can be embedded in $F, x_{0} \rightarrow$ $\left(x_{0}, x_{0}, \cdots\right) \in F$. Taking, on $X_{0}$, the topology induced by $F$, we easily verify that $g: X_{0} \rightarrow\left(E, \mathscr{T}_{0}\right)$ is continuous and so $\left(g(X), \mathscr{T}_{0}\right)$ is separable. Let $K_{0}=$ the closed convex hull, in $(E, \mathscr{T})$, of a countable dense subset of $\left(g(X), \mathscr{T}_{0}\right)$. If $g(X) \not \subset K_{0}$, by separation theorem, there exists an $h \in E^{\prime}$ and $x_{0} \in X$ such that $h \circ g\left(x_{0}\right)>\sup h\left(K_{0}\right)$. Since $\left(E, \mathscr{T}_{0}\right)^{\prime} \supset \bigcup_{n=1}^{\infty} A_{n}, q \circ g\left(x_{0}\right) \leqq \sup q\left(K_{0}\right), \forall q \in \bigcup_{n=1}^{\infty} A_{n}$. Now there exists a net $\left\{h_{\alpha}\right\} \subset \bigcup_{n=1}^{\infty} A_{n}$ such that $h_{\alpha} \rightarrow h$ uniformly on each compact convex subset of $\left(E, \sigma\left(E, E^{\prime}\right)\right)$. From this it follows $h \circ g\left(x_{0}\right) \leqq \sup h\left(K_{0}\right)$, a contradiction. This proves the result.

REMARK 3. If $E$ is metrizable then $\left(E^{\prime}, \sigma\left(E^{\prime}, E\right)\right.$ ) contains a sequence of compact absolutely convex sets whose union is $E^{\prime}$. If $Y$ is a completely regular Hausdorff space containing a $\sigma$-compact dense set and $E=C_{b}(Y)$ with strict topology $\beta_{0}, \beta_{1}$, then it is 
proved in ([3], Theorem 3) that $\left(E^{\prime}, \sigma\left(E^{\prime}, E\right)\right.$ ) has an increasing sequence of absolutely convex compact sets with dense union - here $E$ is not metrizable.

REMARK 4. The function $g: X \rightarrow\left(E, \sigma\left(E, E^{\prime}\right)\right)$, obtained in this theorem, is measurable in the sense of ([2], Def. 4, p. 89).

The next theorem, in some sense, is a generalization of ([9], Theorem 3).

THEOREM 5. Let $E$ be a Hausdorff locally convex space such that there exist, in $\left(E^{\prime}, \sigma\left(E^{\prime}, E\right)\right)$, an increasing sequence $\left\{A_{n}\right\}$ of absolutely convex compact sets whose union is $E^{\prime}$. Suppose $g: X \rightarrow E$ is weakly measurable such that $g \circ f \neq 0$ implies $g \circ f \not \equiv 0$, for every $f \in E^{\prime}$. Then $g(X)$ is contained in a separable subspace of $E$.

Proof. In the notations of Theorem 2, $B_{n}=\left\{h \circ g: h \in A_{n}\right\}$ are compact and metrizable, with the topology of pointwise convergence, and $\mathscr{T}_{0}$ is the metric topology, on $E$, of uniform convergence on $A_{n}$. Proceeding exactly as in Theorem 2, we prove that $g(X)$ is a separable subset of $\left(E, \mathscr{T}_{0}\right)$. Let $F=\left(E, \mathscr{T}_{0}\right)^{\prime}$ and $E_{0}=$ the closed separable subspace, in $(E, \mathscr{T})$, generated by a countable dense subset of $\left(g(X), \mathscr{T}_{0}\right)$. If $g\left(x_{0}\right) \notin E_{0}$ for some $x_{0} \in X$ there exists, by separation theorem, an $h \in E^{\prime}$ such that $h \circ g\left(x_{0}\right)>0$ and $h \equiv 0$ on $E_{0}$. Since $E^{\prime}=\bigcup_{n=1}^{\infty} A_{n} \subset F, h \circ g\left(x_{0}\right) \leqq \sup (h \circ g(X)) \leqq \sup h\left(E_{0}\right)=0$, a contradiction. This proves the result.

In the next theorem we do not assume $H$ to be uniformly bounded ([8], Theorem 4, p. 203).

THEOREM 6. Let $H$ be a pointwise bounded subset of $C(X)$. If $H$ is equicontinuous then, with the topology of pointwise convergence on $X$, its closure in $C(X)$ is compact and metrizable. Conversely if $H$ is sequentially compact then there is a $\mu$-null set $A$ such that $H$ is equicontinuous at each point of the open set $X \backslash A$ of $\left(X, \tau_{\rho}\right)$.

Proof. If $H$ is equicontinuous then its pointwise closed convex hull $H_{0}$, in $R^{X}$, lies in $C(X)$ and is compact and convex, and so the result follows from Theorem 1 .

Conversely suppose $H$ is sequentially compact. Then, by Theorem 1, $H$ is compact and metrizable. By the generalized Egoroff's theorem ([4], p. 198) there exists a 2)-partition of $X=$ $\bigcup_{i=0}^{\infty} X_{i}$, with $\mu\left(X_{0}\right)=0$ and $\mu\left(X_{i}\right)>0, \forall i \geqq 1$ such that $\left.H\right|_{X_{i}}$ is compact in the topology of uniform convergence on $X_{i}, \forall i \geqq 1$. 
$Y_{i}=X_{i} \cap \rho\left(X_{i}\right), i \geqq 1$, are nonvoid, disjoint, open subsets of $\left(X, \tau_{\rho}\right)$ and $\mu(A)=0$, where $A=X \backslash \bigcup_{i=1}^{\infty} Y_{i}$. By the Ascoli Theorem ([1], Ch. X, §2.5), $\left.H\right|_{Y_{2}}$ are equicontinuous for each $i$. The result follows now.

\section{REFERENCES}

1. N. Bourbaki, General Topology, Hermann, Paris, 1966. (Translation by AddisonWesley, Massachusetts.)

2. N. Dinculeanu, Vector Measures, Pergamon Press, New York, 1967.

3. S. S. Khurana, Dunford-Pettis property, J. Math. Anal. Appl., 65 (1978), 361-364.

4. P. A. Meyer, Représentation intégral des fonctions excessives, Résultats de Mokobodzki, Deminaire de Probabilities V, Univ. de Strasbourg, Springer-Verlag, Berlin-New York, Lecture Notes, 198 (1971), 196-208.

5. R. S. Phillips, On weakly compact sets of a Banach space, Amer. J. Math., 65 (1943), 108-136.

6. H.H. Schaefer, Topological Vector Spaces, Springer-Verlag, 1971.

7. A. Ionescu Tulcea, Topologies compatible with liftings, Bull, de la Math. Gréce, 8 (1967), 116-126.

8. - On pointwise convergence, compactness and equicontinuity in the lifting topology I, Zeit Wahrscheinlickheittheorie und Verw. Gebiete, 26 (1973), 197-205.

9. - On pointwise convergence, compactness and equicontinuity II, Adv. Math., 12 (1974), 171-177.

10. A. Ionescu Tulcea, C. Ionescu Tulcea, Topics in the Theory of Liftings, SpringerVerlag, New York, 1969.

11. L. Schwartz, Certaines propriétés des measures sur les espaces de Banach, Sem. Maurey-Schwartz, 1975-76, Ecole Polytechnique, No. 23.

Received August 12, 1978.

The University of Iowa

IowA CITY, IA 52242 



\title{
PACIFIC JOURNAL OF MATHEMATICS
}

\section{EDITORS}

DONALD BABBITT (Managing Editor)

University of California

Los Angeles, CA 90024

\section{HUGO RossI}

University of Utah

Salt Lake City, UT 84112

C. C. MOORE and ANDREW OGG

University of California

Berkeley, CA 94720

\section{J. DUGUNDJI}

Department of Mathematics University of Southern California Los Angeles, CA 90007

R. FINN and J. Milgram

Stanford University Stanford, CA 94305

\section{ASSOCIATE EDITORS}
E. F. BECKENBACH
B. H. NeUmanN
F. WOLF
K. YosHIDA

\section{SUPPORTING INSTITUTIONS}

\author{
UNIVERSITY OF BRITISH COLUMBIA \\ CALIFORNIA INSTITUTE OF TECHNOLOGY \\ UNIVERSITY OF CALIFORNIA \\ MONTANA STATE UNIVERSITY \\ UNIVERSITY OF NEVADA, RENO \\ NEW MEXICO STATE UNIVERSITY \\ OREGON STATE UNIVERSITY \\ UNIVERSITY OF OREGON
}

\author{
UNIVERSITY OF SOUTHERN CALIFORNIA \\ STANFORD UNIVERSITY \\ UNIVERSITY OF HAWAII \\ UNIVERSITY OF TOKYO \\ UNIVERSITY OF UTAH \\ WASHINGTON STATE UNIVERSITY \\ UNIVERSITY OF WASHINGTON
}

The Supporting Institutions listed above contribute to the cost of publication of this Journal, but they are not owners or publishers and have no responsibility for its content or policies.

Mathematical papers intended for publication in the Pacific Journal of Mathematics should be in typed form or offset-reproduced, (not dittoed), double spaced with large margins. Please do not use built up fractions in the text of the manuscript. However, you may use them in the displayed equations. Underline Greek letters in red, German in green, and script in blue. The first paragraph or two must be capable of being used separately as a synopsis of the entire paper. Please propose a heading for the odd numbered pages of less than 35 characters. Manuscripts, in triplicate, may be sent to any one of the editors. Please classify according to the scheme of Math. Reviews, Index to Vol. 39. Supply name and address of author to whom proofs should be sent. All other communications should be addressed to the managing editor, or Elaine Barth, University of California, Los Angeles, California, 90024.

50 reprints to each author are provided free for each article, only if page charges have been substantially paid. Additional copies may be obtained at cost in multiples of 50 .

The Pacific Journal of Mathematics is issued monthly as of January 1966. Regular subscription rate: $\$ 84.00$ a year (6 Vols., 12 issues). Special rate: $\$ 42.00$ a year to individual members of supporting institutions.

Subscriptions, orders for numbers issued in the last three calendar years, and changes of address should be sent to Pacific Journal of Mathematics, P.O. Box 969, Carmel Valley, CA 93924, U.S.A. Older back numbers obtainable from Kraus Periodicals Co., Route 100, Millwood, NY 10546.

PUBLISHED BY PACIFIC JOURNAL OF MATHEMATICS, A NON-PROFIT CORPORATION

Printed at Kokusai Bunken Insatsusha (International Academic Printing Co., Ltd.). 8-8, 3-chome, Takadanobaba, Shinjuku-ku, Tokyo 160, Japan.

Copyright (C) 1979 by Pacific Journal of Mathematics Manufactured and first issued in Japan 


\section{Pacific Journal of Mathematics}

\section{Vol. 83, No. $2 \quad$ April, 1979}

Patrick Robert Ahern, On a theorem of Hayman concerning the derivative of a

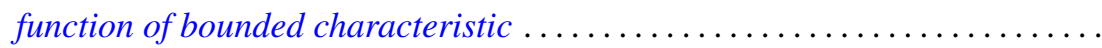

Walter Allegretto, Finiteness of lower spectra of a class of higher order elliptic

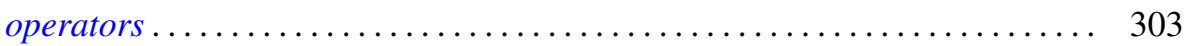

Leonard Asimow, Superharmonic interpolation in subspaces of $C_{c}(X) \ldots \ldots 11$

Steven F. Bellenot, An anti-open mapping theorem for Fréchet spaces . . . . . . . 325

B. J. Day, Locale geometry. . . . . . . . . . . . . . . . . . . . . . . . . . 333

John Erik Fornaess and Steven Krantz, Continuously varying peaking

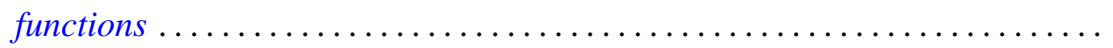

Joseph Leonide Gerver, Long walks in the plane with few collinear points ......

Joseph Leonide Gerver and Lawrence Thom Ramsey, On certain sequences of

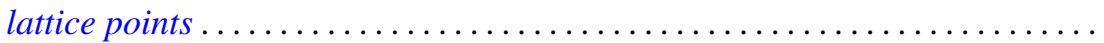

John R. Graef, Yuichi Kitamura, Takaŝi Kusano, Hiroshi Onose and Paul Winton

Spikes, On the nonoscillation of perturbed functional-differential

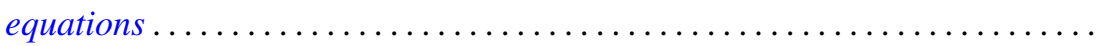

James A. Huckaba and James M. Keller, Annihilation of ideals in commutative

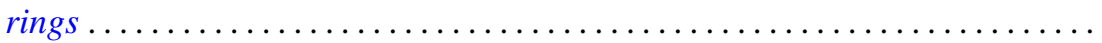

Anzelm Iwanik, Norm attaining operators on Lebesgue spaces . . . . . . . . . . .

Surjit Singh Khurana, Pointwise compactness and measurability . . . .......... 387

Charles Philip Lanski, Commutation with skew elements in rings with

involution.

Hugh Bardeen Maynard, A Radon-Nikodým theorem for finitely additive bounded

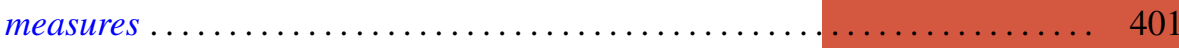

Kevin Mor McCrimmon, Peirce ideals in Jordan triple systems ..

Sam Bernard Nadler, Jr., Joseph E. Quinn and N. Stavrakas, Hyperspaces of compact convex sets.

Ken Nakamula, An explicit formula for the fundamental units of a real pure

sextic number field and its Galois closure ............

Vassili Nestoridis, Inner functions invariant connected components . .

Vladimir I. Oliker, On compact submanifolds with nondegenerate parallel

normal vector fields.

Lex Gerard Oversteegen, Fans and embeddings in the plane.

Shlomo Reisner, On Banach spaces having the property G.L

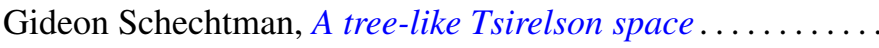

Helga Schirmer, Fix-finite homotopies . . . . . . . . . . . .

Jeffrey D. Vaaler, A geometric inequality with applications to linear forms . .

William Jennings Wickless, $T$ as an $\mathscr{G}$ submodule of $G$.....

Kenneth S. Williams, The class number of $Q(\sqrt{-p})$ modulo 4 , for $p \equiv 3$ (

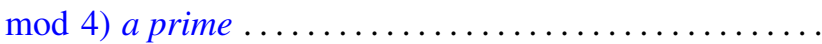

